\title{
Social-Emotional Screening Status in Early Childhood Predicts Elementary School Outcomes
}

\author{
Margaret J. Briggs-Gowan \\ University of Connecticut School of Medicine and Dentistry
}

Follow this and additional works at: https://opencommons.uconn.edu/uchcres_articles Cart of the Psychiatry and Psychology Commons

\section{Recommended Citation}

Briggs-Gowan, Margaret J., "Social-Emotional Screening Status in Early Childhood Predicts Elementary School Outcomes" (2008). UCHC Articles - Research. 23.

https://opencommons.uconn.edu/uchcres_articles/23 


\title{
Social-Emotional Screening Status in Early Childhood Predicts Elementary School Outcomes
}

\author{
Margaret J. Briggs-Gowan, $\mathbf{P h D}^{\mathrm{a}}$ and Alice S. Carter, $\mathbf{P h D}^{\mathrm{b}}$ \\ aDepartment of Psychiatry, University of Connecticut Health Center, Farmington, Connecticut \\ bepartment of Psychology, University of Massachusetts Boston, Boston, Massachusetts
}

\section{Abstract}

OBJECTIVE-The goal was to examine whether children who screen positive for socialemotional/behavioral problems at 12 to 36 months of age are at elevated risk for social-emotional/ behavioral problems in early elementary school.

\begin{abstract}
METHODS-The sample studied $(N=1004)$ comprised an ethnically (33.3\% minority) and socioeconomically (17.8\% living in poverty and $11.3 \%$ living in borderline poverty) diverse, healthy, birth cohort from a metropolitan region of the northeastern United States. When children were 12 to 36 months of age (mean age: 23.8 months; SD: 7.1 months), parents completed the Brief Infant-Toddler Social and Emotional Assessment and questions concerning their level of worry about their child's behavior, emotions, and social development. When children were in early elementary school (mean age: 6.0 years; SD: 0.4 years), parents completed the Child Behavior Checklist and teachers completed the Teacher Report Form regarding behavioral problems. In a subsample $(n=389)$, parents reported child psychiatric status.
\end{abstract}

RESULTS-Brief Infant-Toddler Social and Emotional Assessment screen status and parental worry were associated significantly with school-age symptoms and psychiatric disorders. In multivariate analyses that included Brief Infant-Toddler Social and Emotional Assessment status and parental worry, Brief Infant-Toddler Social and Emotional Assessment scores significantly predicted all school-age problems, whereas worry predicted only parent reports with the Child Behavior Checklist. Children with of-concern scores on the problem scale of the Brief InfantToddler Social and Emotional Assessment were at increased risk for parent-reported subclinical/ clinical levels of problems and for psychiatric disorders. Low competence scores predicted later teacher-reported subclinical/clinical problems and parent-reported disorders. Worry predicted parent-reported subclinical/clinical problems. Moreover, the Brief Infant-Toddler Social and Emotional Assessment identified $49.0 \%$ of children who exhibited subclinical/clinical symptoms according to teachers and $67.9 \%$ of children who later met the criteria for a psychiatric disorder.

CONCLUSIONS-Screening with a standardized tool in early childhood has the potential to identify the majority of children who exhibit significant emotional/behavioral problems in early elementary school.

Copyright $(2008$ by the American Academy of Pediatrics

Address correspondence to Margaret J. Briggs-Gowan, PhD, Department of Psychiatry, University of Connecticut Health Center, 263 Farmington Ave, MC-1410, Farmington, CT 06030. briggsgowan@ psychiatry.uchc.edu.

Financial Disclosure: At the time of the design of the study and the collection of the data, the BITSEA was an unpublished measure and the authors did not receive royalties. However, copyright of the BITSEA is now licensed to Harcourt Assessment and the authors receive royalties. 


\section{Keywords}

screening; medical home; behavioral problems; Brief Infant-Toddler Social and Emotional Assessment; parental concern

Recent decades have witnessed major advances in the identification and treatment of developmental delays in infants and toddlers. Supporting these advances, the American Academy of Pediatrics recommends routine screening for developmental delays in pediatric primary care settings, to identify children with delays in language, motor, or cognitive development or with autism spectrum disorders. ${ }^{1,2}$ Identified children can be referred for early intervention services, an entitlement for children with developmental delays. ${ }^{3}$ Notably, an independent American Academy of Pediatrics recommendation for social-emotional screening is under consideration. ${ }^{2}$ However, states vary considerably with respect to availability of early intervention services for children with social-emotional/behavioral problems. Progress also is evident in the advancement of the medical home model, which supports comprehensive, coordinated, culturally competent care in primary care settings, a key component of which is the detection of both developmental delays and social-emotional/ behavioral problems. ${ }^{4}$ Increasing attention to social-emotional/behavioral problems is driven by greater awareness that young children with social-emotional/behavioral problems are at increased risk for a host of negative outcomes, including psychiatric disorders ${ }^{5-8}$ and poorer academic achievement. ${ }^{5}$ Effective early intervention models for social-emotional/behavioral problems are now available. ${ }^{9-12}$

Screening for social-emotional/behavioral problems in pediatric primary care has been shown to be feasible ${ }^{13,14}$ and effective in enhancing detection rates. ${ }^{15}$ Brief parent-report screening tools are now available for identifying social-emotional and behavioral problems in infants and toddlers. These include the Ages and Stages Social-Emotional questionnaire ${ }^{16}$ and the Brief Infant-Toddler Social and Emotional Assessment (BITSEA), ${ }^{17,18}$ as well as the Parents' Evaluation of Developmental Status, ${ }^{19}$ which includes questions that address parental concerns about the child's "behavior" and "getting along with others." With increasing support for the medical home and its emphasis on early detection of developmental and social-emotional/behavioral problems in pediatric primary care, empirical evidence concerning the capacity of screening in early childhood to identify children who continue to have problems in early elementary school is essential. Prediction of emotional/behavioral problems in early elementary school on the basis of BITSEA status and parental worry at 12 through 36 months was examined in a longitudinal, representative, community birth cohort. It was hypothesized that BITSEA status and parental worry would significantly predict school-age problems reported by parents and teachers.

\section{METHODS}

\section{Participants}

The sample comprises participants from a healthy birth cohort, ascertained at 12 to 36 months of age and monitored to school age. The sample was selected randomly from birth records provided by the State of Connecticut Department of Public Health. Eligible children were born to families living in the New Haven-Meriden standard metropolitan statistical area. Children were ineligible if no parent could complete the survey in English $(n=50)$, the family had moved out of Connecticut $(n=116)$, or a sibling was sampled $(n=277)$. Children at high risk for developmental delays because of low birth weight $(<2200 \mathrm{~g})$, prematurity ( $<36$ weeks), serious birth complications (eg, anoxia or resuscitation), or genetic disorders were excluded $(n=675) .{ }^{20}$ At school age, a subsample was selected for additional assessment, including psychiatric interviews (A.S.C., PhD, K. J. McCarthy, BA, R. J. 
Wagmiller, PhD, J. Bosson-Heenan, BA, S. M. Horwitz, PhD, and M.J.B.-G., PhD, manuscript in preparation, 2007). This subsample was enriched for social-emotional/ behavioral problems through overinclusion of children reported by parents and/or teachers to have social-emotional/behavioral problems or possible language delays in early childhood and/or elementary school; however, all subsample analyses used statistical weights that adjusted for the probability of selection, and the results are generalizable to the full sample from which the subsample was drawn.

Of 1491 eligible children, 1280 (86\%) participated in year 1. Participants were sociodemographically similar to families living in the region. ${ }^{20}$ Elementary school surveys were completed by $81.6 \%$ of year 1 participants. Most parents $(81.8 \%)$ provided permission to invite their child's teacher to participate, and $83.8 \%$ of invited teachers participated. Statistical weights were applied to all analyses to adjust for significant but minimal response and retention biases related to ethnicity and parent education. Analyses used data for participants with both year 1 and early elementary school surveys $(N=1004)$ and excluded 47 children who were not between 12 and 36 months of age and therefore were outside the age range of the BITSEA national normative values.

In year 1, the mean age of the analyzed sample was 23.8 months (SD: 7.1 months). One half $(50.1 \%)$ of the sample was male. For the early elementary school wave, the mean age was 6.0 years (SD: 0.4 years). The sample was diverse with respect to ethnicity $(66.7 \%$ white, $17.5 \%$ black, $5.0 \%$ Hispanic, $1.6 \%$ Asian, $7.7 \%$ multiethnic minority, and $1.3 \%$ other), respondent education (24.0\% with high school education or less), marital status (21.0\% single), and poverty status (17.8\% living below the poverty line and $11.3 \%$ living in borderline poverty). Ninety-eight percent of children had visited a health care professional in the previous year. Child health care was usually obtained from a physician's office (74.5\%), health maintenance organization (6.1\%), community health center $(5.4 \%)$, public health clinic $(1.2 \%)$, or hospital $(12.0 \%)$. Few parents $(1.7 \%)$ reported receiving services for socialemotional/behavioral problems in year $1 .{ }^{21}$

\section{Procedures}

Parents completed a survey about their child and family life in year 1 and again after children had entered elementary school. Although most children were in kindergarten when the survey was completed, some were in grade 1. Parents did not receive any feedback from the surveys. With parental permission, teachers were invited to complete a questionnaire about the child. To minimize the potential impact of transient difficulties related to the transition to school on teachers' ratings, teachers were contacted in the spring. Parents in an intensive subsample were interviewed about child psychiatric disorders by research assistants. Parents received $\$ 25$ for completing the early childhood survey and $\$ 30$ for completing the school-age survey. Teachers received \$25. Participants in the intensive subsample received $\$ 100$. Informed consent procedures were used with all subjects. All methods were approved by institutional review boards.

\section{Measures}

BITSEA-The BITSEA, a nationally standardized, normative value-referenced, 42-item screener for 1- to 3-year-old children, was completed in year 1. The 31-item BITSEA problem scale assesses social-emotional/behavioral problems such as aggression, defiance, overactivity, negative emotionality, anxiety, and withdrawal. The 11-item BITSEA competence scale assesses social-emotional abilities such as empathy, prosocial behaviors, and compliance. Lower scores indicate lesser competence. The BITSEA has excellent testretest reliability $(r=0.79-0.92)$, very good interrater reliability $(r=0.55-0.78),{ }^{18}$ and adequate internal consistency (Cronbach's $\alpha=.79$ for the problem scale and $\alpha=.65$ for the 
competence scale). ${ }^{17}$ The BITSEA has demonstrated validity in discriminating children with clinically significant problems from matched control subjects. ${ }^{18}$ Cutoff points for "of concern" were calculated in 6-month age bands according to child gender by using cutoff points established with the national standardization sample. For the BITSEA problem scale, the of-concern cutoff point indicates scores of $\geq 75$ th percentile. For the BITSEA competence scale, the of-concern cutoff point indicates scores of $<15$ th percentile, which suggests that delays in social-emotional competence may be present.

Parental Worry-Parents answered 3 questions concerning worry about their child ("How worried are you about your child's behavior, social development, and emotional development?") The word "worry" was used, rather than "concern," because in field testing some parents understood the phrase "How concerned are you about X?" as meaning "How much is X something that is of interest or importance to you?" Questions were rated on a 5point scale (from $1=$ not at all worried to $5=$ extremely worried). High parental worry was indicated by a rating of $\geq 3$ on $\geq 1$ worry question, a level previously associated with helpseeking. ${ }^{22}$

Child Behavior Checklist and Teacher Report Form-School-age emotional/ behavioral problems were assessed with the parent-report Child Behavior Checklist (CBCL)/6-18 and the teacher-report Teacher Report Form (TRF)/6-18. ${ }^{23}$ These measures have acceptable reliability and validity. Clinically significant problems were indicated by internalizing, externalizing, or total scores in the subclinical ( $T$ scores of 60-62) or clinical $\left(T\right.$ scores of $\geq 63$ ) range. ${ }^{23}$

Diagnostic Interview Schedule for Children, Version IV-The structured parent Diagnostic Interview Schedule for Children, Version IV, ${ }^{24}$ was used to assess the presence of Diagnostic and Statistical Manual of Mental Disorders, Fourth Edition child psychiatric disorders with impairment in the intensive subsample. Common childhood disorders were assessed, including separation anxiety, generalized anxiety disorder, specific phobia, social phobia, depression, attention-deficit/hyperactivity disorder, oppositional-defiant disorder, and conduct disorder.

Center for Epidemiologic Studies Depression Inventory-Parental depressive symptoms were measured with the 20-item Center for Epidemiologic Studies Depression Inventory. ${ }^{25}$ The Center for Epidemiologic Studies Depression Inventory has acceptable reliability and validity. Scores of $\geq 16$ were considered to indicate elevated depressive symptoms.

Beck Anxiety Inventory-Parental anxiety symptoms were measured on a 4-point scale (from "not at all bothered" to "severely bothered") with the 21-item Beck Anxiety Inventory. ${ }^{26}$ The Beck Anxiety Inventory has acceptable reliability and validity. A clinical cutoff point of 16 was used.

\section{RESULTS}

\section{Rates of Problems}

In year $1,10.4 \%$ of children had scores in the of-concern range on the BITSEA problem and/or competence scales and high parental worry, 22.9\% had of-concern BITSEA scores but not worry, and 6.4\% had worry only. Most children with worry (62.2\%) also had ofconcern BITSEA scores. Only $31.4 \%$ of children with of-concern BITSEA scores had high parental worry levels. 


\section{Prediction of Symptom Scores}

BITSEA continuous scores and parental worry correlated significantly with parent reports on the CBCL and teacher reports on the TRF at school age (Table 1).

\section{Bivariate Analyses}

Of-concern BITSEA scores were associated significantly and strongly with parent- and teacher-reported problems at school age (Table 2). For example, children with of-concern BITSEA problem scale scores were $\sim 4.5$ times more likely than children with scores below the cutoff point to have subclinical/clinical CBCL scores. Nearly $31 \%$ of children with ofconcern BITSEA problem scale scores had persistent problems, as indicated by high scores on the CBCL at school age. Moreover, children with persistent problems represented 54.8\% of all children with later problems on the CBCL. BITSEA competence scale scores also were associated significantly with CBCL status. Furthermore, children with of-concern scores on the BITSEA problem or competence scales represented $64 \%$ of the children later identified with the CBCL.

BITSEA status was associated significantly with later psychiatric disorders (Table 2). Forty percent of children with of-concern BITSEA scores later met the criteria for a disorder, and the BITSEA identified $67.9 \%$ of the children who met the criteria for disorders.

BITSEA status significantly predicted teacher-reported subclinical/clinical problems on the TRF (Table 2). Nearly $40 \%$ of children with of-concern BITSEA problem and/or competence scale scores had subclinical/clinical TRF scores. This persistent group represented $49.0 \%$ of all teacher-reported problems. Parental worry in early childhood significantly predicted later symptoms and disorders reported by parents but not those reported by teachers.

\section{Multivariate Analyses}

To examine the extent to which BITSEA scores and worry uniquely predicted school-age problems, 3 multivariate logistic regression models were computed. Each model included BITSEA problem status, BITSEA competence status, and worry. These models also included sociodemographic factors (high school education or less, poverty, marital status, minority ethnicity, child gender, child age, and number of children in the home) and parental depressive and anxiety symptoms. Covariates were included if they were associated with the given outcome at $P<.10$.

In the first model, of-concern BITSEA problem scale scores and high worry levels were significant and unique predictors of scores in the subclinical/clinical range on the parentreport CBCL, controlling for sociodemographic factors and parental symptoms (Table 3). BITSEA problem and competence scale scores but not worry levels significantly predicted school-age psychiatric disorders, controlling for other factors. Finally, BITSEA competence scale scores significantly predicted subclinical/clinical scores on the teacher-report TRF.

\section{Early Identification of Problems With the BITSEA and Worry}

To provide additional insight into the pattern of findings over time, the proportion of children with school-age problems who were identified in early childhood with the BITSEA and/or worry was examined. As shown in Fig 1, the majority of children who were reported to have significant emotional/behavioral problems at school age had of-concern BITSEA scores in early childhood. 


\section{DISCUSSION}

This study was conducted as part of a community survey, which afforded an opportunity to observe the natural course of early-emerging social-emotional/behavioral problems. The findings suggest that more than one half of the children who were identified by parents and/ or teachers as having emotional/behavioral problems in early elementary school were already experiencing social-emotional/behavioral problems or low competence levels at 12 to 36 months. Specifically, one half of the children with significant problems according to their teachers and $68 \%$ of those with parent-reported psychiatric disorders had of-concern BITSEA scores in early childhood. Therefore, screening in early childhood with a brief, validated, normative value-referenced checklist is an important strategy for detecting socialemotional/behavioral problems that endure into early elementary school.

Multivariate analyses examined whether BITSEA status and parental worry uniquely predicted school-age social-emotional/behavioral problems. Identifying children on the basis of social-emotional and behavioral problems and competencies seems to be more effective in predicting school-age outcomes than is the use of broad sociodemographic risk factors, such as poverty. Moreover, BITSEA of-concern status, and to a lesser extent parental worry, uniquely predicted school-age problems when parental depressive and anxiety symptoms, which have been associated with overreporting of child symptoms, ${ }^{27}$ were controlled. Additional evidence that depressive symptoms contributed to teacher-reported problems emphasizes the importance of identifying and treating depression in parents of young children. Supporting the importance of screening for both problems and competencies, BITSEA competence scale scores predicted teacher-reported problems, whereas BITSEA problem and competence scale scores both predicted parent-reported psychiatric disorders. Therefore, very young children who lag behind their peers in social-emotional competencies seem to be at risk for social-emotional/behavioral problems that are later identified by elementary school teachers.

Additional results indicated that, although parental worry in early childhood was a significant predictor of later parent-reported problems, it was not predictive of teacherreported problems. Some previous research suggested that parental concern is a sensitive indicator of emotional/behavioral problems in older children but is less sensitive with children $<4.5$ years of age. ${ }^{28}$ Worry and concern may be less sensitive in early childhood because parents have difficulty distinguishing true "problem" behaviors from normative misbehaviors. ${ }^{22}$ Indeed, less than one third of parents who reported high levels of problems on the BITSEA also reported being worried about their child. Although insight into parental worry is particularly useful for framing discussions with parents, child behavior-based screening tools are essential for early detection.

Approximately one third of children had of-concern scores on the BITSEA problem or competence scale at 12 to 36 months. Although this rate may seem high, approximately one half of those children still had clinically significant problems at school age. Given evidence that the BITSEA has acceptable sensitivity and specificity as a screener for early childhood emotional/behavioral problems, ${ }^{17}$ it is likely that some children exhibited clinically significant problems that resolved by school age. Consistent with the medical home approach, measures such as the BITSEA are not intended as stand-alone tools. Discussions with parents about screening results, combined with clinical observations, developmental history, and ongoing developmental surveillance, are crucial for clarifying whether clinically significant problems are present. Clinically significant problems are indicated by behaviors that are exhibited with great frequency or intensity, occur across multiple settings or caregiving relationships, cause parental worry, and/or have begun to interfere with the child's developmental progress or family routines. ${ }^{18,29}$ 


\section{CONCLUSIONS}

Until quite recently, there was controversy regarding the existence of clinically significant social-emotional/behavioral problems in children $<36$ months of age. The findings presented increase the knowledge base regarding the early emergence and persistence of socialemotional/behavioral problems; one half of the problems identified by teachers in early elementary school were presaged by parent reports at 12 to 36 months of age. At a time when evidence-based early intervention programs exist, ${ }^{9-12}$ these results strongly support routine screening to identify infant/toddler social-emotional/behavioral problems. However, research is needed to evaluate the feasibility and effectiveness of first- and second-stage screening on early detection, engagement in appropriate services, and reduction of problem persistence.

\section{Acknowledgments}

This study was supported by National Institute of Mental Health grants R01MH55278 and R01MH66645.

Special thanks go to Kimberly McCarthy and Lauren Wakschlag, $\mathrm{PhD}$, for their input regarding this manuscript and to Sarah M. Horwitz for methodologic contri butions to this study.

\section{Abbreviations}

BITSEA Brief Infant-Toddler Social and Emotional Assessment

CBCL Child Behavior Checklist

TRF Teacher Report Form

\section{REFERENCES}

1. American Academy of Pediatrics; Committee on Children with Disabilities. Developmental surveillance and screening of infants and young children. Pediatrics. 2001; 108(1):192-196. [PubMed: 11433077]

2. American Academy of Pediatrics. Identifying infants and young children with developmental disorders in the medical home: an algorithm for developmental surveillance and screening. Pediatrics. 2006; 118(1):405-420. [PubMed: 16818591]

3. Public Law 108 - 446: Individuals With Disabilities Education Improvement Act of 2004.

4. American Academy of Pediatrics; Ad Hoc Task Force on Definition of the Medical Home. The medical home. Pediatrics. 1992; 90(5):774. [PubMed: 1408554]

5. Campbell SB, Spieker S, Burchinal M, Poe MD. Trajectories of aggression from toddlerhood to age 9 predict academic and social functioning through age 12. J Child Psychol Psychiatry. 2006; 47(8): 791-800. [PubMed: 16898993]

6. Campbell SB, Shaw DS, Gilliom M. Early externalizing behavior problems: toddlers and preschoolers at risk for later maladjustment. Dev Psychopathol. 2000; 12(3):467-488. [PubMed: 11014748]

7. Fox NA. Temperament and early experience form social behavior. Ann N Y Acad Sci. 2004; 1038:171-178. [PubMed: 15838111]

8. Shaw DS, Keenan K, Vondra JI. Developmental precursors of externalizing behavior: ages 1 to 3. Dev Psychol. 1994; 30(3):355-364.

9. Gross D, Fogg L, Webster-Stratton C, Garvey C, Julion W, Grady J. Parent training of toddlers in day care in low-income urban communities. J Consult Clin Psychol. 2003; 71(2):261-278. [PubMed: 12699021]

10. Kelleher KJ, Campo JV, Gardner WP. Management of pediatric mental disorders in primary care: where are we now and where are we going? Curr Opin Pediatr. 2006; 18(6):649-653. [PubMed: 17099365] 
11. Reid MJ, Webster-Stratton C, Baydar N. Halting the development of conduct problems in Head Start children: the effects of parent training. J Clin Child Adolesc Psychol. 2004; 33(2):279-291. [PubMed: 15136193]

12. Thomas R, Zimmer-Gembeck MJ. Behavioral outcomes of parent-child interaction therapy and Triple P-positive parenting program: a review and meta-analysis. J Abnorm Child Psychol. 2007; 35(3):475-495. [PubMed: 17333363]

13. Jellinek MS, Murphy MJ, Little M, Pagano M, Comer DM, Kelleher KJ. Use of the Pediatric Symptom Checklist to screen for psychosocial problems in pediatric primary care. Arch Pediatr Adolesc Med. 1999; 153(3):254-260. [PubMed: 10086402]

14. Earls MF, Hay SS. Setting the stage for success: implementation of developmental and behavioral screening and surveillance in primary care practice: the North Carolina Assuring Better Child Health and Development (ABCD) Project. Pediatrics. 2006; 118(1) Available at: www.pediatrics.org/cgi/content/full/118/1/e183.

15. Murphy JM, Ichinose C, Hicks RC, et al. Utility of the Pediatric Symptom Checklist as a psychosocial screen to meet the federal Early and Periodic Screening, Diagnosis, and Treatment (EPSDT) standards: a pilot study. J Pediatr. 1996; 129(6):864-869. [PubMed: 8969728]

16. Squires, J.; Bricker, D.; Twombly, E. The ASQ-SE User's Guide. Brookes Publishing Co; Baltimore, MD: 2002.

17. Briggs-Gowan MJ, Carter AS, Irwin JR, Wachtel K, Cicchetti DV. The Brief Infant-Toddler Social and Emotional Assessment: screening for social-emotional problems and delays in competence. J Pediatr Psychol. 2004; 29(2):143-155. [PubMed: 15096535]

18. Briggs-Gowan, MJ.; Carter, AS. BITSEA Brief Infant-Toddler Social and Emotional Assessment Examiner's Manual. Harcourt Assessment; San Antonio, TX: 2006.

19. Glascoe, FP. Parents' Evaluations of Developmental Status: A Method for Detecting and Addressing Developmental and Behavioral Problems in Children. Ellsworth \& Vandermeer Press; Nashville, TN: 1997.

20. Briggs-Gowan MJ, Carter AS, Skuban EM, Horwitz SM. Prevalence of social-emotional and behavioral problems in a community sample of 1- and 2-year-old children. J Am Acad Child Adolesc Psychiatry. 2001; 40(7):811-819. [PubMed: 11437020]

21. Horwitz SM, Gary LC, Briggs-Gowan MJ, Carter AS. Do needs drive services use in young children? Pediatrics. 2003; 112(6):1373-1378. [PubMed: 14654612]

22. Ellingson KD, Briggs-Gowan MJ, Carter AS, Horwitz SM. Parent identification of early emerging child behavior problems: predictors of sharing parental concern with health providers. Arch Pediatr Adolesc Med. 2004; 158(8):766-772. [PubMed: 15289249]

23. Achenbach, TM.; Rescorla, LA. Manual for the ASEBA School-Age Forms and Profiles. University of Vermont, Research Center of Children, Youth, and Families; Burlington, VT: 2001.

24. Shaffer D, Fisher P, Lucas C, Dulcan MK, Schwab-Stone ME. NIMH Diagnostic Interview Schedule for Children, Version IV (NIMH DISC-IV): description, differences from previous versions of reliability of some common diagnoses. J Am Acad Child Adolesc Psychiatry. 2000; 39(1):28-38. [PubMed: 10638065]

25. Radloff LS. The CES-D scale: a self-report depression scale for research in the general population. Appl Psychol Meas. 1977; 1(3):385-401.

26. Beck AT, Epstein N, Brown G, Steer RA. An inventory for measuring clinical anxiety: psychometric properties. J Consult Clin Psychol. 1988; 56(6):893-897. [PubMed: 3204199]

27. Briggs-Gowan MJ, Carter AS, Schwab-Stone M. Discrepancies among mother, child, and teacher reports: examining the contributions of maternal depression and anxiety. $\mathrm{J}$ Abnorm Child Psychol. 1996; 24(6):749-765. [PubMed: 8970908]

28. Glascoe FP. Parents' evaluation of developmental status: how well do parents' concerns identify children with behavioral and emotional problems? Clin Pediatr (Phila). 2003; 42(2):133-138. [PubMed: 12659386]

29. Weitzman CC, Leventhal JM. Screening for behavioral health problems in primary care. Curr Opin Pediatr. 2006; 18(6):641-648. [PubMed: 17099364] 


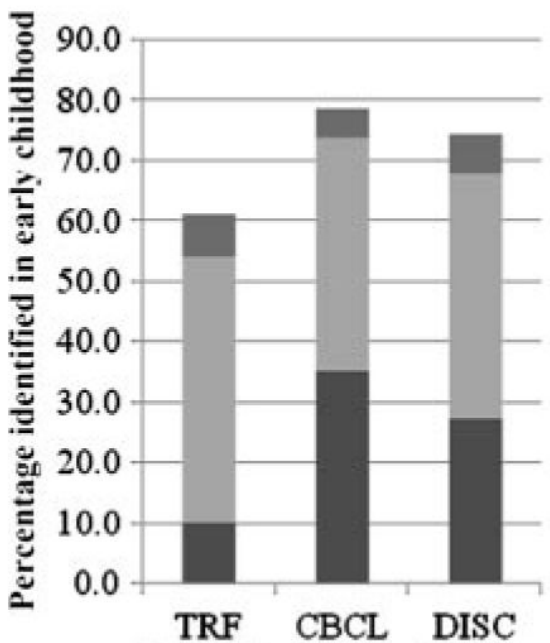

= Detected by worry only

Elementary school outcome

\section{= Detected by BITSEA only}

- Detected by BITSEA and

Worry

FIGURE 1.

Early identification of school-age problems and worry in early childhood, according to BITSEA. 
TABLE 1

Correlations Between Continuous BITSEA Scores at 12 to 36 Months and School-Age Outcomes

\begin{tabular}{lrc}
\hline & \multicolumn{2}{c}{ Correlation } \\
\cline { 2 - 3 } & $\mathbf{C B C L}(\boldsymbol{n}=\mathbf{9 7 3})$ & $\mathbf{T R F}(\boldsymbol{n}=\mathbf{6 9 7})$ \\
\hline BITSEA problem scale & $0.41^{a}$ & $0.17^{a}$ \\
BITSEA competence scale & $-0.17^{a}$ & $-0.24^{a}$ \\
Parental worry & $0.29^{a}$ & 0.06 \\
\hline
\end{tabular}

${ }^{a}{ }_{P<0001}$. 


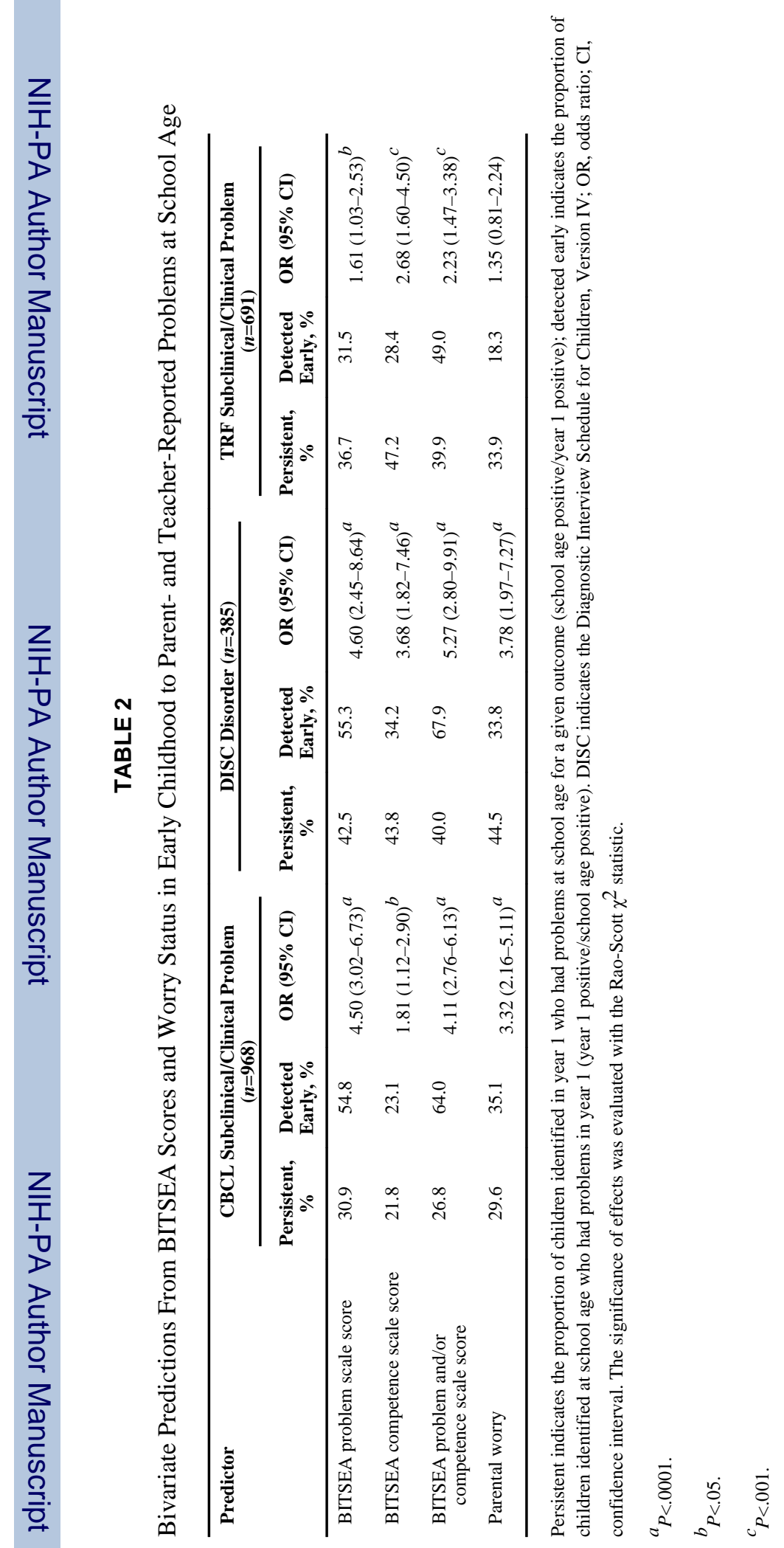

Pediatrics. Author manuscript; available in PMC 2011 May 5. 


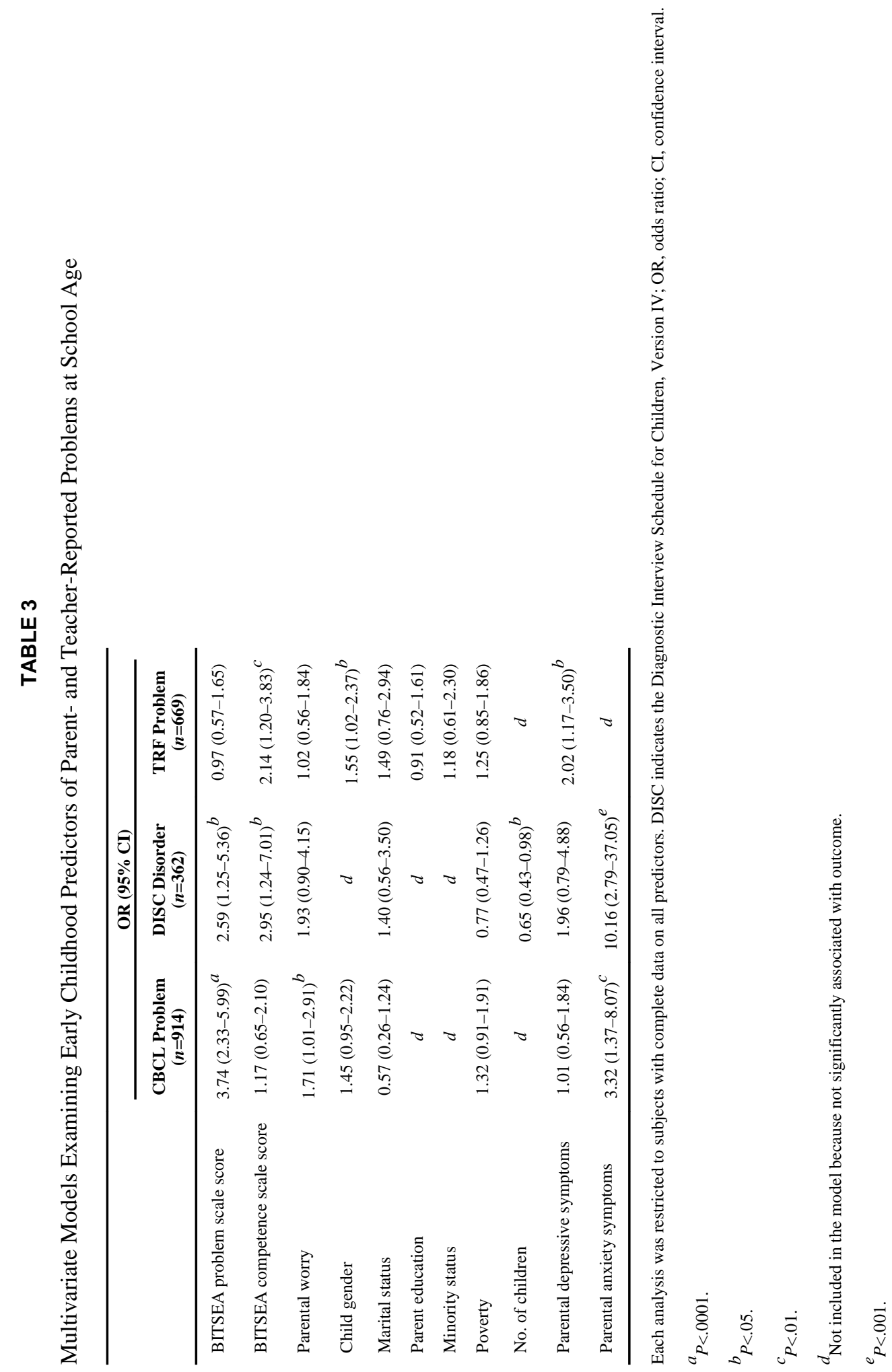

Pediatrics. Author manuscript; available in PMC 2011 May 5. 